\title{
Study on Scale and Corrosion Inhibition Performance of Ethane-1,2-diaminium O,O'-dicyclohexyldithiophosphate
}

\author{
Chuan Lai ${ }^{1,2,3,4, *}$, Wei Wang ${ }^{2,3}$, Shenjiang Lv ${ }^{2,3}$, Yuanfang Deng ${ }^{2,3}$, Xiaoying Gan ${ }^{2,3}$, Wan Gou ${ }^{1,3,4}$ \\ ${ }^{1}$ Eastern Sichuan Sub-center of National Engineering Research Center for Municipal Wastewater \\ Treatment and Reuse, Key Laboratory of Characteristic Plants Development and Research of Higher \\ Education Institutes of Sichuan, Sichuan University of Arts and Science, Dazhou 635000, China \\ ${ }^{2}$ DaZhou Quality Technical Supervision and Inspection Testing Center, Quality Supervision and \\ Inspection Center of Selenium Enriched Products in Sichuan Province, Dazhou 635000, China \\ ${ }^{3}$ Technology R \& D Sichuan Sizhong Basalt Fiber Co., Ltd., Dazhou 635000, China \\ ${ }^{4}$ Laboratories of Fine Chemicals and Surfactants in Sichuan Provincial Universities, Sichuan \\ University of Science and Engineering, Zigong, 643000, China \\ *E-mail: $\underline{\text { laichuanemail@163.com }}$
}

doi: $10.20964 / 2020.11 .05$

Received: 1 July 2020 / Accepted: 20 August 2020 / Published: 30 September 2020

Ethane-1,2-diaminium O,O'-dicyclohexyldithiophosphate (Et-DDD) as novel corrosion and scale inhibitor was successfully synthesized by cyclohexanol $\left(\mathrm{C}_{6} \mathrm{H}_{11} \mathrm{OH}\right)$ reaction with phosphorus pentasulfide $\left(\mathrm{P}_{2} \mathrm{~S}_{5}\right)$ and ethylenediamine $\left(\mathrm{H}_{2} \mathrm{NCH}_{2} \mathrm{CH}_{2} \mathrm{NH}_{2}\right)$ in toluene $\left(\mathrm{PhCH}_{3}\right)$, while the corrosion and scale inhibition performance of Et-DDD were studied and evaluated in detailed. Study results show that Et-DDD is a mixed-type inhibitor for Q235 steel ( 2235$)$ in $\mathrm{H}_{2} \mathrm{SO}_{4}$ and $\mathrm{HCl}$ solution. It can be found that the scale inhibition and corrosion inhibition efficiency increased with Et-DDD concentration increasing. Meanwhile, the scale and corrosion inhibitor also can be act as a surfactant, the surface tension of Et-DDD at critical micelle concentration of $14.15 \mathrm{mmol} \mathrm{L}^{-1}$ is $33.47 \mathrm{mN} \mathrm{m}^{-1}$.

Keywords: Synthesis; Corrosion; Scale; Inhibition; Steel.

\section{$\underline{\text { FULL TEXT }}$}

(C) 2020 The Authors. Published by ESG (www.electrochemsci.org). This article is an open access article distributed under the terms and conditions of the Creative Commons Attribution license (http://creativecommons.org/licenses/by/4.0/). 